\title{
Integrating Issues of Diversity Across the Curriculum for All Pre-Service Teachers
}

\author{
Jihea Kang \\ Michigan State University \\ kangji5@msu.edu
}

\begin{abstract}
Teaching across difference is a major issue in teacher education today due to the increasing cultural diversity of K-12 students. In this article, I consider how teacher education programs can integrate diversity issues across the curriculum for both hegemonic "majority" pre-service teachers (e.g., white, English dominant, middle-class, female) as well "minority" pre-service teachers from diverse cultural and linguistic backgrounds. I argue that "mainstream" teacher candidates can learn cultural knowledge, skills and political awareness through diversity-infused curricula. I also assert that diversity-infused curricula provide safe "counter-spaces" for "minority" teacher candidates to examine their internalized oppression. However, I also acknowledge the tensions and challenges in implementing diversity-infused curricula, including individual resistance, structural issues regarding high stakes accountability, and incoherent, piecemeal implementation of diversity-infused curricula. I describe how teacher educators could combine diversity-infused curriculum with pre-service teachers' critical reflections and pedagogical stances during coursework as well as field experiences in order to foster pre-service teachers' teaching for social justice.
\end{abstract}

Keywords: Diversity-infused Curriculum; Pre-service Teacher Education; Teaching for Diversity and Social Justice; Diversifying Teaching Force

\section{Introduction}

By the year 2020, $40 \%$ of U.S. school students will be culturally, linguistically, racially, and ethnically diverse in the context of transnationalism and im/migration (Rodriquez, Adams, \& Zimmer, 2016). In contrast, the "mainstream" teaching force remains white, middle class, female, and native-born, and monolingual (DiAngelo, 2004). To close this cultural and linguistic gap between students and teachers, teacher educators have endeavored to diversify the profile of teachers and conducted research to best prepare teacher candidates to teach for diversity and social justice in diverse contexts.

Yet different stakeholders in various political and school contexts have shared dissimilar views of how schools and education should prepare diverse students for active economic, social, and political roles in the U.S. society. Further, teacher educators and researchers also have had different views on how teacher education programs should prepare for teachers to teach those culturally and linguistically diverse students. This reflects that different level of diversity and changes in its conceptions of what diversity means related educational equity over the years in the field of teacher education. In 1972, for instance, the vision of diversity and multicultural education articulated by the American Association of Colleges for Teacher Education (AACTE) in the position paper, "No One Model American." In its document, it values cultural pluralism, diversity, and individual uniqueness

Received (March 30, 2017), Review Result (September 1, 2017), Accepted (September 11, 2017) 
instead of assimilation. Since this call for addressing diversity issues in the field of teacher education, there has been a strong push for learning diversity and teaching for social justice by standards of National Council for Accreditation of Teacher Education (NCATE, Cochran-Smith et al., 2008). However, according to reviews on teacher education programs' diversity-related initiative in their program curricula (Cochran-Smith, 2003; Sleeter, 2001), most programs either have few courses addressing diversity issues, or they have only a couple of scattering diversityinfused courses. Research findings suggest that this significant vision has been disconnected within and across teacher education curricula (Villegas \& Lucas, 2002; Milner, 2009). In other words, while some programs explicitly focus on issues of diversity across curriculum and fieldwork, other programs have one or two separated diversity-infused coursework and fieldwork for pre-service teachers (Milner, 2009; Villegas \& Lucas, 2002). This reflects varied perspectives of teacher education programs and teacher educators on issues of diversity.

Villegas and Lucas (2002) noted that the teacher education curriculum should consistently address issues of diversity across various coursework for prospective teachers. They argued that issues of diversity and social justice should be at the center of the curricula, rather than peripheral. Similarly, Milner (2009) argued that prospective teachers should be able to challenge their deficit-based predisposition on culturally and linguistically diverse students through "conceptual repertoire of diversity" in the classroom; that is, awareness of concepts such as color-blindness, cultural conflicts, meritocracy, deficit conceptions, and expectations. Milner (2009) asserted that teacher education programs should intentionally challenge and address teachers' conceptual repertories of diversity because these conceptions shape, and impact their teaching.

Therefore, while challenging, integrating issues of diversity in teacher education curricula have many benefits for students and teachers. To that end, teacher education curricula should explicitly address teaching for diversity and social justice across the board. Also, this can be done through building teacher candidates' cultural knowledge, skills and awareness through diversity-focused curriculum to teach culturally and linguistically diverse students. In this article, I address the benefits and challenges to implement the vision of diversity-integrated curricula in teacher education programs, and suggest implications for teacher educators.

\section{Why Diversity-infused Curriculum in Teacher Education}

\subsection{Preparing "Mainstream" Pre-service Teachers to Teach Diverse Students}

Pre-service teachers' prior experiences and attitudes about diversity have deep effects on the way they eventually teach their future students. For example, research on the predispositions of "mainstream" pre-service teachers show that many of such "mainstream" prospective teachers enter the teacher education program with deficit perspectives. First, mainstream pre-services teachers often have insufficient knowledge and awareness of prejudice and discrimination, especially racism and its impact on culturally and linguistically diverse students' learning (e.g., Sleeter, 2001); second, they have low expectations for the academic achievement of students of color (Lew, 2006); third, they have limited knowledge about culturally and linguistically diverse communities, and fear discussing issues on race and racism (Gusa, 2010); and finally they often lack an understanding of themselves as cultural beings, or of classrooms as culturally-contested sites (Florio-Ruane, 2001). With these predispositions, teacher candidates often fall into familiar habits and perspectives based on their learning experiences in K-12 contexts. Some pre-service teachers may also assume, or expect that they will work with students similar to 
them in culture, race, language, or class, and find themselves challenged with teaching the increasing number of culturally and linguistically diverse students in classrooms.

To address these issues, teacher education programs should explicitly address teacher candidates' assumptions on culturally and linguistically diverse students and challenge their deficit-oriented perspectives. As such, providing courses that solely focus on teaching methods, or one or two isolated diversity courses would not be sufficient. Rather, persistent diversity-infused curricula integrated into their coursework, community service and teaching practicum, would benefits mainstream teachers by challenging their preconceptions and raising their cultural and political awareness in order to better teach culturally and linguistically diverse students (e.g., Villegas \& Lucas, 2002).

Studies have closely examined how those "mainstream" (e.g., White, middleclass, English-speaking) prospective teachers learn to raise their cultural and political awareness through diversity-focused coursework and challenge their assumptions. In other words, diversity-integrated curricula support the changes of mainstream pre-service teachers' deficit-saturated views on culturally and linguistically diverse students. However, the question still remains how those mainstream teacher educators would be interested in enacting their teaching with respect to culturally responsive and sustaining pedagogy, rather than merely "best practice" for all students.

Research evidence suggests that the coursework that incorporate critical multicultural education into specific subject and method coursework would engage pre-service teachers in critical dialogues in their cultural being and teaching. For example, in Florio-Ruane's study (2001), mainstream white pre-service teachers began to critically examine their own racial identity and issues on race and racism while reading multicultural literature. The coursework encouraged them to write and share their autobiographical accounts on their racialized lives as well as others in the literature. Similarly, McVee (2004) addressed how mainstream white teachers engaged themselves with literary texts with multicultural topics. McVee explored how in-service and pre-service teachers in literacy method coursework read and reflect their beliefs and experiences in relation to issues of race and culture through autobiographical accounts. Referred as "Narrative as dynamic," McVee highlighted that using autobiographically-grounded narratives is helpful for pre-service teachers to respond to the literature, uncover issues of power in the texts, and finally make connections to the lived reality of their own and that of their future students.

As the majority of prospective teachers come from mainstream groups, teacher education programs should continuously pursue ways to better prepare mainstream teachers to teach culturally and linguistically diverse students. However, scholars also have raised concerns that diversity-infused curricula in teacher education programs tend to focus on the needs of mainstream teacher candidates (Sleeter, 2001). There is relatively little research on the perspectives that pre-service teachers from culturally, racially, and linguistically diverse backgrounds bring to their teaching practice for culturally and linguistically diverse students. Likewise, issues such as diversifying the teaching force and retaining diverse teachers tend to be marginalized in the relevant literature on teacher education. To solve this issue, teacher education programs should create a safe counter-space for diverse teacher candidates to address their needs and experiences without fear of judgments by their peers or instructors in teacher preparation programs, or during their field experiences (Kang, 2017; Solórzano, Ceja, \& Yosso, 2000).

I believe diversity-integrated coursework could provide marginalized students to voice their silenced voice and experiences, and counter dominant views. While discussing African American college students' racialized experiences, counter- 
stories, and college racial climate, Solórzano, Ceja, and Yosso (2000) referred such safe space as "counter-space." Solórzano, Ceja, and Yosso (2000) argued the importance of counter-stories of students of color to challenge the dominant narratives and Whiteness (i.e., unearned privilege related to their race and ethnicity) in college campuses. They also emphasized the needs of creating academic and social "counter-spaces" that "serve as sites where deficit notions of people of color can be challenged and where a positive collegiate racial climate can be established and maintained" (p. 70). Along with his claim, I agree with the importance of diversity-integrated curricula in teacher preparation program, and its roles in creating counter-space for all prospective teachers. Yet teacher educators should be also aware that there could be potential hesitance and resistance of marginalized students towards voicing and challenging predominantly deficit perspectives on themselves, and how they could respond to such resistance and hesitance.

\subsection{Diversifying Teaching Force}

A growing body of research suggests that teachers who are positioned as "other" to the mainstream tend to show a strong commitment to teaching for diversity and social justice for the education of culturally and linguistically diverse students, who like themselves, are not members of "mainstream" groups (Villegas \& Irvine, 2010). Therefore, teacher education programs should recruit more diverse teacher candidates. Diverse teachers are better equipped than mainstream teachers to serve as role models for culturally and linguistically diverse students students. Further, diverse teachers tend to have better cultural understandings of culturally and linguistically diverse students and also hold higher academic expectations for their culturally and linguistically diverse students' achievements in comparison to mainstream teachers.

However, research does not does propose that teacher or students should be allocated based on their race and ethnicity. Rather, the research findings suggest that teachers from diverse backgrounds can use their experience and perspectives as pedagogical resources. While acknowledging "mainstream" teachers' blinded awareness on issues of race, class, and gender, the diversity-focused curricula also go beyond issues on race, class, and gender. For example, racialized experiences of English language learners (ELLs) and increasing number of non-native English speaking teachers (NNESTs) in the context of growing teacher mobility and $\mathrm{im} /$ migration would add multifaceted dimensions into the diversity-focused curricula. Several studies in the field of language studies and TESOL (Teaching English for Speakers of Other Languages) have explored how issues of race and racism have closely linked to the language ideologies (e.g., Kubota \& Lin, 2006). One such language hegemony is native speaker fallacy that native English speaking teachers would be an ideal and better teacher as modeling ELLs' language learning. However, research findings suggest counter-evidence that NNESTs can be more empathetic towards ELLs' language learning, and knowledgeable in second language acquisition and learning compared to that of native English speaking teachers (Kubota \& Lin, 2006). Taking NNESTs' diverse experiences and perspectives into account in diversity-integrated curricula would be also significant in teacher preparation programs.

Nonetheless, studies have noted that we should not assume that diverse teacher candidates promptly know how to address the needs of culturally and linguistically diverse students, or that diverse teachers should be assigned to play a role of cultural insider on culturally and linguistically diverse students' lived experiences and needs for academic achievement (Kohli, 2014). For instance, Kohli (2014) examined how a black, Latina, and Asian American female teacher candidate experience racism during their K-12 schooling, and how they began to unpack and 
challenge their internalized racism in their K-12 education. Kohili (ibid) found that teacher candidates' internalized racism played a critical role in understanding their perspectives as well as expectations of learning of students of color. After having critical dialogues about their own internalized racism in their teacher preparation program, these participants were able to develop pedagogy that was aware of both their own experiences with racism and their expectations towards the experiences of culturally and linguistically diverse students. Kohli (ibid) further argued that the invisibility of racial inequality should be explicitly addressed in diversity-focused curricula in order for racial "minority" teachers to shift and challenge their own assumptions and prejudice. In so doing, diversity-focused coursework serve as an important pedagogical space to reflect and use their insight as a tool to understand culturally and linguistic diverse students' experience and to challenge racism in schools.

Diversity-infused coursework alone may not be sufficient for many prospective teachers to raise a critical awareness and challenge their predisposed understandings on various social construct (e.g., race, class, gender, language). For instance, using a life-historical counter-storytelling approach, I examined a Korean female preservice teacher's experiences in a U.S. teacher preparation program (Kang, 2017). Despite the teacher education program's strong promotion of diversity in curricula and field experiences, the participant encountered many challenges due to her perceived language proficiency and communication style in a U.S. higher educational context. The participant responded to her challenges in several ways. For instance, she felt pressure to internalize deficit-oriented narratives and assimilate into dominant cultural norms, and second, by resisting racial stereotyping. My findings suggest that teacher educators not only need to implement diversity-infused curriculum in teacher education program and field experiences, but also need to create counter-spaces for linguistic and ethnic/racial minority preservice teachers. As shown in this case study, despite the best intentions and implementation of a diversity-focused curriculum, there will always be challenges and tensions in addressing issues of diversity and social justice in teacher education programs. In the following section, I address the challenges that need to be acknowledged before teacher education programs can effectively educate teacher candidates.

\section{Tensions and Challenges in Implementing Diversity-infused Curriculum in Teacher Education}

The research literature in North American contexts raises many concerns about addressing issues of diversity and social justice in teacher preparation programs. Major challenges include: 1) "mainstream" pre-service teachers" active, or passive resistance against unlearning privilege, power, and oppression, 2) structural issues such as policy that demands outcome and teacher quality based on standardized tests, 3) teacher education programs' understanding teaching for social justice as a radical ideology that politicizes teacher education, and 4) partiality of diversity curriculum within teacher education programs.

First, Ball and Cohen (1996) identified why supposedly promising diversityinfused curriculum enactment may fail, even if pre-service teacher candidates' cultural and linguistic backgrounds are taken into account and instructors provide concrete guidance. The success of the curriculum often depends on individual teacher candidates' responses to diversity issues. Despite teacher educators' conscientious efforts to raise mainstream teacher candidates' critical consciousness and equip them with culturally responsive and sustaining pedagogy (Ladson-Billings 1995; Paris, 2012), multiple studies show that many mainstream pre-service 
teachers' resist these courses and curricula. Picower (2009) describes how mainstream pre-service teachers responded and negotiated their own positioning in relation to issues of privilege, power, and oppression in a multicultural education course by not only showing passive resistance, but an active protection of whiteness in the classroom. Sleeter (2001) notes that teacher educators may have to move beyond obsessively "transforming" dominant white teachers' disposition, and instead recruit diverse teacher candidates who demonstrate beliefs, knowledge, and commitment to working with culturally and linguistically diverse students.

Beyond resistance on the part of mainstream teacher-candidates, tensions also arise from the macro-level of the educational policy and institutional structure. For example, Agee (2004), describes the experiences of an African-American English teacher who used her cultural awareness, knowledge, and skills to work with culturally and linguistically diverse through diversity-focused curricula, and made explicit efforts to engage her students in issues of critical diversity through multicultural literature for three years. Agee (ibid) found that despite the teacher's conviction in teaching for social justice, the teacher expressed frustration with school demands for mandated assessments. Agee (ibid) noted that ethnic and linguistic minority teachers' ideal role in teaching for diversity is often an "imagined role," thwarted in a discursive space by the mainstream construction of a teacher role, the demands of the school contexts, and teachers' own commitment to teaching for diversity and social justice. Since the U.S. Department of Education promotes a high-stakes accountability game for teachers across subject areas (e.g., math, science, and reading), many teachers are under tremendous pressure to meet standardized test outcomes to prove their professional quality.

Another challenge is that teacher educators have varied meanings and definitions of diversity and social justice in pre-service teacher education. Teaching for social justice and diversity often refers to teachers' commitment and belief in working with less privileged students and ensuring educational equality and equity (CochranSmith et al., 2008). However, teacher candidates and teacher educators may view "teaching for social justice" as an attack on white middle-class Americans. They may argue that white privilege and different forms of oppression do not exist any more. In 2005, for example, teacher candidates filed a lawsuit against their instructor, who was teaching a conceptual framework of social justice at the School of Education (The New York Sun, May 31 st, 2005; Gollnick, 2008). As a form of neo-racism, the teacher candidates argued that they were being indoctrinated by leftist ideological messages.

A final challenge is that even if teacher candidates are fully qualified to teach culturally and linguistically diverse students and even if educational policies also support and fund teaching for social justice, limited or partial diversity-infused teacher education curricula in teacher preparation programs may send mixed messages. As Grossman et al., (2008) points out, prospective teachers often view subject content and teaching for social justice as distinctive forms of knowledge and beliefs because diversity-related courses and subject method courses are kept separate but equal.

To sum up, many concerns and disagreements exist on the meaning of social justice and implementing diversity-infused curricula in teacher education programs and among teacher educators. These challenges reflect not only different assumptions about diversity in teacher education, but also various perspectives on what teacher candidates should know, care about, and believe. Therefore, it is clear that all teacher candidates should address these issues comprehensively in their education before teaching diverse student populations. 


\section{Envisioning Diversity-infused Curriculum in Teacher Education}

Scholars in the field of teacher education emphasize that educators need to understand what perspectives exist around issues of teaching for diversity among diverse teacher education stakeholders (Cochran-Smith, 2003). Diversity should be placed at the center of the teacher education curricula and teacher candidates' cross cultural fieldwork experiences, rather than relegated to the periphery as an optional learning and teaching practice (Milner, 2009). Undeniably, teacher candidates need to learn theories of teaching for diversity and social justice in their coursework and apply their understanding during field experiences in diverse classrooms. In this section, I address three implications of diversity-focused curricula for teacher candidates' understanding and teaching practice.

First, diversity-focused curricula may often provide fragmented forms of knowledge to teacher candidates if it is not connected to their teaching practice. As such, Grossman et al. (2008) proposed a teacher capacity model and curriculum shifts to 1) dismantle the dichotomy between subject areas and social justice, 2) focus on supporting novice teachers to develop and improve teaching practices, and 3 ) preparing teachers to explicit give attention to teaching low achieving students. As Milner (2009) noted, when teacher education programs work towards a more common and integrated curriculum that encompasses issues of diversity, prospective teachers should be able to build their own "conceptual repertories of diversity" and also transform their teaching practices.

The second implication is to provide teacher candidates with culturally responsive/relevant/sustaining, anti-oppressive pedagogy to meet the needs of culturally and linguistically diverse students. Ladson-Billings (1995) proposed culturally relevant pedagogy where teachers help "students to accept and affirm their cultural identity while developing critical perspectives that challenge inequalities that schools (and other institutions) perpetuate" (p. 469). Culturally relevant pedagogy should help students develop in three ways: academic achievement, cultural competence, and skills to understand and critique the existing social order. She argued that any theory of pedagogy cannot avoid dealing with raising academic achievement, and that "culturally relevant pedagogy must provide a way for students to maintain their cultural integrity while succeeding academically" (p. 476). Furthermore, teachers must help students to "recognize, understand, and critique current social inequalities" (p. 476). Lee (2007) also offered an example of successful teaching using this approach. She not only advanced discussions surrounding what it means to be a culturally responsive teacher, but also questioned what it means to be a learner. Drawing from a threeyear project where she herself taught one high school English class, Lee (2007) explored how the Cultural Modeling Project was employed to intervene and reinvent the nature of English instruction at a failing urban high school. Drawing on the notion of "cultural funds of knowledge" (Moll \& Gonzales, 2004) Lee (2007) noted that teacher educators, curriculum designers of K-12 schools, and teachers should be able to actively connect to students' (in)visible background knowledge to address the demands of complex problem solving in various subject matters. Lee (2007) also illuminated how schools can be transformative "sites of renewal for all its members" (p. 5) - if explicit instruction and cultural modeling support culturally and linguistically diverse students' academic learning through their cultural funds of knowledge.

More recently, Paris (2012) notes that culturally sustaining pedagogy "seeks to perpetuate and foster - to sustain - linguistic, literate, and cultural pluralism as part of the democratic project of schooling and as a needed response to demographic and social change" (p. 88). In other words, Paris' culturally sustaining pedagogy 
proposes focusing on sustaining pluralism among culturally and linguistically diverse students' backgrounds through education. Raising teacher candidates' awareness and encouraging them to choose their own pedagogical stances would help them to disrupt any assumptions related to linguistic and cultural ownership and teaching practice.

Finally, diversity-integrated curriculum should be closely tied to teaching practice, and should support pre-service teachers' field experiences in meaningful ways. It is important that teacher education programs maintain their efforts to build supportive relationships with K-12 schools and in-service teachers' communities. More importantly, teacher education programs should ensure that diversity-infused curricula provide well-planned opportunities for pre-service teachers to question their assumptions during their teaching practice in the field, rather than simply observing, helping the mentor teacher, or tutoring students (Sleeter, 2001). According to Lucas and Grinberg (2008), diversity-integrated curriculum is theoretically desirable. Yet efforts to integrate issues of diversity and social justice may manifest superficially in actual practice. Teacher educators and pre-service teachers should share knowledge, awareness, skills, belief, and commitments about addressing these issues. One strategy that Lucas and Grinberg (2008) proposed is "special enrichment activities." These activities include teacher candidates' professional development through diversity-integrated seminars, guest lectures, and field trips during their fieldwork. Furthermore, follow-up guided discussions are necessary for teacher candidates to critically reflect on their understanding, assumptions, and their teaching practice for culturally and linguistically diverse students. Scaffolding reflections before, during, and after fieldwork experiences creates opportunities for pre-service teachers to understand that students' attitudes, behaviors, and academic outcomes are not simply the characteristics or efforts of the students, but are situated in relationships and interactions between what students and teachers do and believe.

\section{Conclusion}

In this article, drawing on a full review of the literature, I show how a diversityinfused teacher education curriculum has the potential for supporting all pre-service teachers' understanding of issues surrounding diversity in the classroom and teaching force. Further, I illustrated what sorts of challenges and tensions exist and how we should address these challenges in teacher preparation programs. Additionally, I discuss the implications of diversity-infused curricula in enhancing teachers' capacity for using valuable pedagogy, and also bridging their theoretical learning to their teaching practice.

Certainly, there exist inevitable and necessary partiality and resistance as we, teacher educators, push ourselves to teach for social justice and change. As Kumashiro (2002) noted, teacher candidates should be able to attain certain dispositions and capacity to teach for diversity and social justice, and yet teacher candidates' transformative changes are not always smooth or comfortable. Teacher candidates also need a certain amount of knowledge and political awareness, as well as of their limitations.in order to create powerful change in themselves, their students, and their communities.

\section{References}

[1] J. Agee, "Negotiating a teaching identity: An African American teacher's struggle to teach in test-driven contexts", The Teachers College Record, vol. 106, no. 4, (2004), pp. 747-774.

[2] D. L. Ball and D. K. Cohen, "Reform by the book: What is: Or might be: The role of curriculum materials in teacher learning and instructional reform?", Educational Researcher, vol. 25, no. 9, (1996), pp. 6-14. 
[3] M. Cochran-Smith, "The multiple meanings of multicultural teacher education: A conceptual framework", Teacher Education Quarterly, (2003), pp. 7-26.

[4] M. Cochran-Smith, S. Feiman-Nemser, D. J. McIntyre and K. E. Demers, "Handbook of research on teacher education: Enduring questions in changing contexts", NY:Routledge, (2008).

[5] R. DiAngelo, "The production of whiteness in education: Asian international students in a college classroom", The Teachers College Record, vol. 108, no. 10, (2006), pp. 1960-1982.

[6] D. M. Gollnick, "Teacher capacity for diversity. Handbook of research on teacher education: Enduring questions in changing contexts", vol. 249, (2008).

[7] P. Grossman, M. McDonald, K. Hammerness and M. Ronfeldt, "Dismantling dichotomies in teacher education. Handbook of research on teacher education: Enduring questions in changing contexts", vol. 243, (2008).

[8] S. Florio-Ruane, "Teacher education and the cultural imagination: Autobiography, conversation, and narrative", Routledge, (2001).

[9] J. Kang, "Creating a Counter-Space through Listening to and Learning from a Korean Pre-service Teacher's Experience”, Journal of Educational Issues, vol. 3, no. 1, (2017), pp. 141-154.

[10] R. Kohli, "Unpacking internalized racism: Teachers of color striving for racially just classrooms", Race Ethnicity and Education, vol. 17, no. 3, (2014), pp. 367-387.

[11] R. Kubota and A. Lin, "Race and TESOL: Introduction to concepts and theories", TESOL quarterly, vol. 40, no. 2, (2006), pp. 471-493.

[12] K. K. Kumashiro, "Troubling education: Queer activism and anti-oppressive pedagogy", Psychology Press, (2002).

[13] G. Ladson-Billings, "Toward a theory of culturally relevant pedagogy", American Educational Research Journal, vol. 32, no. 3, (1995), pp. 465-491.

[14] C. Lee, "Culture, Literacy, and Learning: Taking Bloom in the Midst of the Whirlwind", Teachers College Press, (2007).

[15] J. Lew, "Asian Americans in class: Charting the achievement gap among Korean American youth", New York, NY: Teachers College Press, (2006).

[16] T. Lucas and J. Grinberg, "Responding to the linguistic reality of mainstream classrooms: Preparing all teachers to teach English language learners", Handbook of research on teacher education: Enduring questions in changing contexts, (2008), pp. 606-636.

[17] M. B. McVee, "Narrative and the exploration of culture in teachers' discussions of literacy, identity, self, and other", Teaching and Teacher education, vol. 20, no. 8, (2004), pp. 881-899.

[18] H. V. Milner, "What does teacher education have to do with teaching? Implications for diversity studies", Journal of Teacher Education, vol. 61, no. 1, (2009), pp. 118-131.

[19] L. C. Moll and N. Gonzalez, "Engaging life: A funds-of-knowledge approach to multicultural education", Handbook of research on multicultural education, vol. 2, (2004), pp. 699-715.

[20] D. Paris, "Culturally sustaining pedagogy: A needed change in stance, terminology, and practice", Educational Researcher, vol. 41, no. 3, (2012), pp. 93-97.

[21] B. Picower, "The unexamined whiteness of teaching: How white teachers maintain and enact dominant racial ideologies", Race Ethnicity and Education, vol. 12, no. 2, (2009), pp. 197-215.

[22] S. C. Rodriguez, M. Adams and K. Zimmer, "Fostering Diverse Praxis: Pre-service Teachers", Handbook of Research on Teacher Education and Professional Development, vol. 210, (2016).

[23] D. Solórzano, M. Ceja and T. Yosso, "Critical race theory, racial microaggressions, and campus racial climate: The experiences of African American college students", Journal of Negro Education, (2000), p. 60-73.

[24] C. E. Sleeter, I. N. La Vonne and K. K. Kumashiro, "Diversifying the teacher workforce: Preparing and retaining highly effective teachers", NY: Routledge, (2014).

[25] A. M. Villegas and T. Lucas, "Preparing culturally responsive teachers rethinking the curriculum", Journal of teacher education, vol. 53, no. 1, (2002), pp. 20-32.

\section{Author}

Jihea Kang, is a Ph.D. candidate in the Department of Teacher Education at Michigan State University. Her research interests include transnational and intercultural lived experiences, and multilingual teachers' language learning and teaching in educational contexts and teacher education. 
International Journal of Education and Learning

Vol.6, No.2 (2017) 